
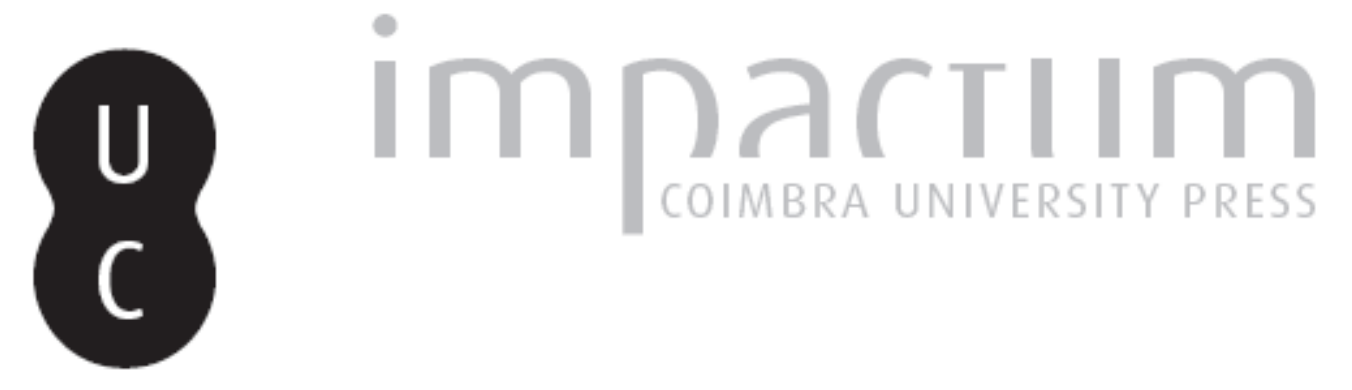

\title{
Platão no Ribatejo: notas sobre as Notas
}

Autor(es): $\quad$ Namora, Ricardo

Publicado por: Centro de Literatura Portuguesa

URL persistente:

URI:http://hdl.handle.net/10316.2/29989

DOI:

DOI:http://dx.doi.org/10.14195/2182-8830_1-1_6

Accessed : $\quad$ 26-Apr-2023 12:59:56

A navegação consulta e descarregamento dos títulos inseridos nas Bibliotecas Digitais UC Digitalis, UC Pombalina e UC Impactum, pressupõem a aceitação plena e sem reservas dos Termos e Condições de Uso destas Bibliotecas Digitais, disponíveis em https://digitalis.uc.pt/pt-pt/termos.

Conforme exposto nos referidos Termos e Condições de Uso, o descarregamento de títulos de acesso restrito requer uma licença válida de autorização devendo o utilizador aceder ao(s) documento(s) a partir de um endereço de IP da instituição detentora da supramencionada licença.

Ao utilizador é apenas permitido o descarregamento para uso pessoal, pelo que o emprego do(s) título(s) descarregado(s) para outro fim, designadamente comercial, carece de autorização do respetivo autor ou editor da obra.

Na medida em que todas as obras da UC Digitalis se encontram protegidas pelo Código do Direito de Autor e Direitos Conexos e demais legislação aplicável, toda a cópia, parcial ou total, deste documento, nos casos em que é legalmente admitida, deverá conter ou fazer-se acompanhar por este aviso.

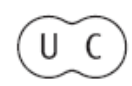




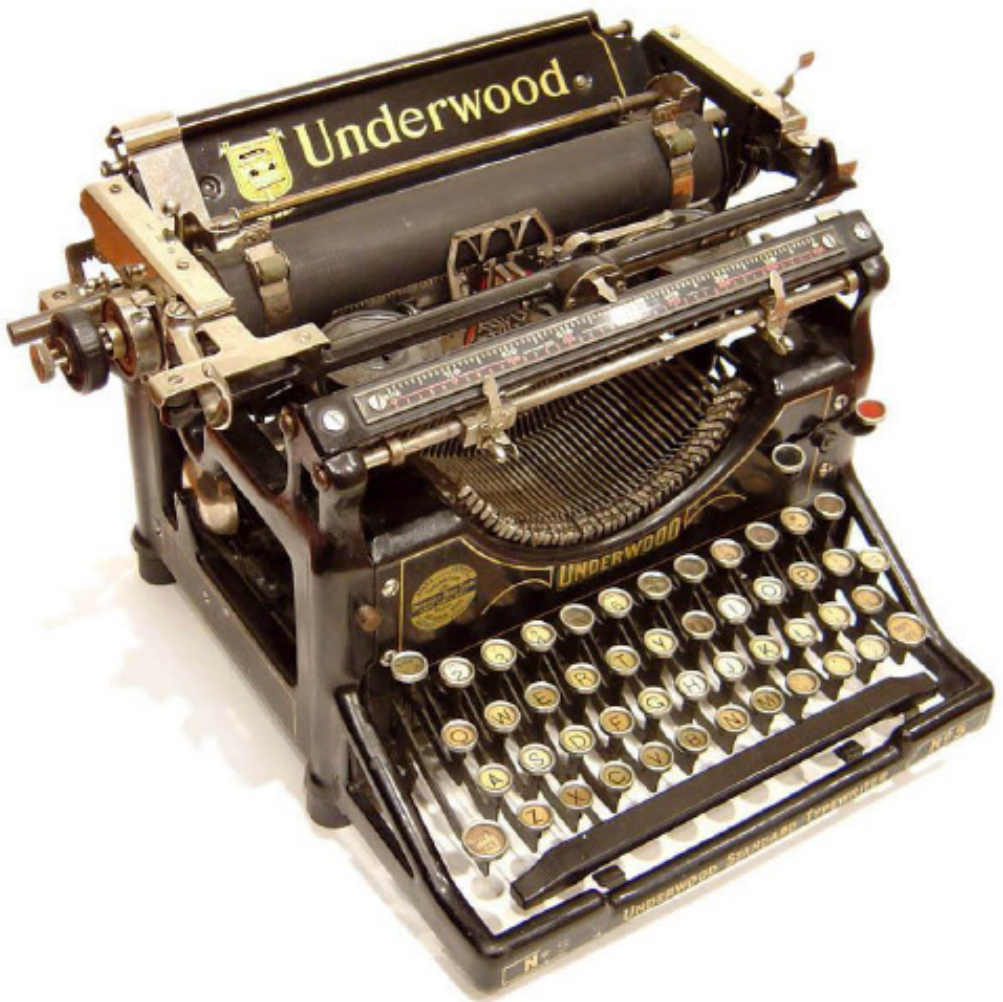

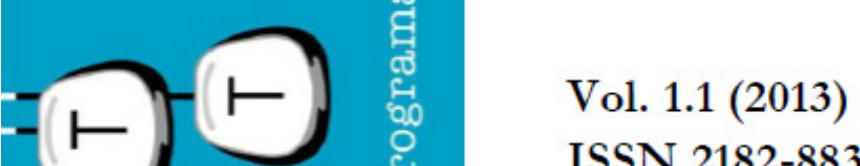

ISSN 2182-8830

'Estranhar Pessoa com

as Materialidades da Literatura'

Orgs. Manuel Portela \&

Osvaldo Manuel Silvestre 


\title{
Platão no Ribatejo: Notas sobre as Notas RICARDO NAMORA
}

\author{
CLP | Universidade de Coimbra
}

\begin{abstract}
Resumo
A partir das "Notas para a recordação do meu mestre Caeiro", de Álvaro de Campos, pretendem discutir-se as implicações da atribuição de um estatuto tutelar ao primeiro no contexto do simpósio da heteronomia. Para além disso, serão descritos outros tópicos, a saber: i) a possibilidade de uma arqueologia dos heterónimos pelo lado dos afectos; ii) a materialidade individual correlativa dos heterónimos; iii) as possibilidades materiais do real e respectivas consequências epistemológicas. Palavras-chave: Simpósio; Afectos; Mestre; Discípulos.
\end{abstract}

\section{Abstract}

Springing from "Notas para a recordação do meu mestre Caeiro", by Álvaro de Campos, this is a discussion on the implications that follow from the attribution of guardianship status to Caeiro within the heteronomy symposium. Moreover, other important topics will be described, notably: i) the possibility of an archaeology of the heteronyms from the affections standpoint; ii) the correlative individual materiality of the heteronyms; iii) the material possibilities of the real and its epistemological consequences. Keywords: Symposium; Affections; Master; Disciples.

$\mathbf{P}$ arece ser consensual, na paisagem crítica que circunda (e muitas vezes constitui) Fernando Pessoa, que uma explicação satisfatória do fenómeno dos heterónimos é instrumental para a compreensão da sua obra. Um dos principais problemas, neste caso particular, é o de descrever correctamente aquilo que conta como uma "explicação satisfatória" e, por inerência, construir - ainda que de modo meramente indicativo - uma hierarquia inteligível. Pessoalmente, continuo convencido (como, presumo, muitas das pessoas que procuram essa explicação) de que a melhor maneira de compreender alguma coisa consiste, nas palavras de Wittgenstein, em saber "como prosseguir". Neste sentido preciso, ter pelo menos uma ideia de como tudo se passou parece ter consequências cruciais sobre o modo como se prossegue a partir desse ponto e, sobretudo, para onde se vai. Como é sabido, Fernando Pessoa poupou-nos muitos dissabores com a carta de 13 de Janeiro de 1935 ao seu "prezado Camarada" Casais Monteiro, uma espécie de artifício cuja eficácia assenta na mania tão ocidental de tomar por certo que as auto-descrições são mais autênticas e válidas do que descrições feitas por terceiros. A proximidade do testemunho ao declarante (ou vice-versa) tem sido, no caso desta carta, amplamente comentada e discutida, posta em causa 
como veículo de um embuste ou, na melhor das hipóteses, olhada com desconfiança e cepticismo. A herança de Pessoa, contudo, excedeu em muito a famosa carta, e o que restou, no fim de contas, foi a vontade que muita gente teve para "prosseguir" apesar daquela.

Uma das explicações mais interessantes, e injustamente esquecidas, a propósito da questão dos heterónimos é a de Agostinho da Silva em Um Fernando Pessoa, de 1959. ${ }^{1}$ Segundo ele, um dos problemas mais prementes de Pessoa qua pessoa tem a ver com uma sórdida estrutura dilemática que extrapola a existência quotidiana de uma maneira tão drástica que a solução para ela não pode ser senão radical. Dentro deste cenário de asfixia, "o que se punha em primeiro lugar, para Pessoa, era a questão de saber como haveria possibilidade de se não suicidar, tendo caído no meio em que caíra e não vendo maneira dele se livrar" (Silva, 1996: 34). O que parece estar subjacente a esta suposição é a recuperação de uma célebre máxima recorrente em situações de perigo, "running for life", e sua transformação numa forma igualmente literal de "writing for life". Não é, no entanto, apenas a premência de "escrever para sobreviver" que gera a concepção estética da vida que Pessoa produz, mas antes as consequências que dela emanam. De acordo com Agostinho da Silva,

tão grave era a questão para Pessoa, tão vital a sua resposta, que as soluções, como por um novo baixar do Espírito, não surgiram, como seria natural num escritor, sob a forma de ensaio ou poesia: surgiram encarnadas, surgiram como gente, e, como indivíduos autónomos, puderam, independentemente da vontade de Pessoa, não da sua vontade crítica, é evidente, mas da sua vontade criadora, anunciar o que eram como solução e, até, travar polémicas entre si ou com o próprio Fernando Pessoa. O que havia de feminino em Pessoa, e nele tanto importa, se paria em poetas. (Silva, 1996: 34, 35)

Existem dois pontos que me interessam particularmente nesta descrição: desde logo, o facto de coisas que escapam à vontade criadora de pessoas terem a possibilidade de se relacionarem entre si; e, em segundo lugar, a associação do tópico da criação artística a ideias de feminilidade e, por inerência, de maternidade, sensualidade e afectos. Se a isto juntarmos alguns aspectos da dinâmica relacional descrita por Freud como o "romance familiar", teremos talvez um bom ponto de partida para uma descrição do teatro heterónimo em Pessoa e, em particular, do objecto central que se pretende discutir neste texto.

Deste modo, interessa-me mais, para os efeitos e propósitos deste ensaio, dirigir a minha atenção para certas implicações do fenómeno dos

${ }^{1}$ Agostinho da Silva, Um Fernando Pessoa, 3a Edição, Lisboa, Guimarães Editores, 1996 [1959]. 
heterónimos, do que propriamente discutir a natureza desse mesmo fenómeno. Existe, neste contexto particular, um sítio preciso em que a possibilidade efectiva de "soluções" que surgiram "encarnadas" e "como gente" travarem peculiares "polémicas entre si e com o próprio Fernando Pessoa": as "Notas para a recordação do meu mestre Caeiro", de Álvaro de Campos. ${ }^{2}$ Evidentemente, existem outros sítios onde um tal exercício foi levado a cabo, por Pessoa e até por terceiros, como por exemplo em $O$ Virgem Negra, de Mário Cesariny. ${ }^{3}$ Mas as "Notas", pela sua natureza, permitem associar o Pessoa orquestrador de um simpósio e o Pessoa parturiente da descrição de Agostinho da Silva de uma forma que talvez exceda uma consideração estrita e, diríamos, tradicional, do fenómeno dos heterónimos. Para além disso, purifica os instintos sensuais da explicação de Cesariny, no sentido de uma aceitação psicológica, e não meramente sexual, dos afectos recíprocos das pessoas de Pessoa.

Mas vamos por partes. Caeiro morre, tuberculoso, em 1915 em Lisboa. Consensualmente tido como a figura tutelar do teatro dos heterónimos, Caeiro é, como o seu nome indicia, o "caiador", o poeta de existência simples e espartana cujo sistema filosófico, que tanto se esforçou por ocultar, serve de inspiração aos demais actores. Agostinho da Silva caracteriza esse "nãosistema" axiomático como uma reacção ao "vício de pensar", resumindo a doutrina de Caeiro da seguinte maneira:

O vício de pensar é porventura dos mais daninhos que se abateu sobre a humanidade e quanto mais felizes seríamos se pudéssemos regressar a tempos que, simbolicamente, chamaríamos de ante-pré-socráticos, quando a filosofia ainda não aparecera com a pretensão de substituir o conto de fadas, ou até mesmo antes disso, quando o conto de fadas ainda não aparecera com a pretensão de substituir a vida. (Silva, 1996: 58)

É, pois, a metafísica bastante que há em não pensar em nada que seduz, num primeiro impacto, os discípulos. Campos, um duplo inconstante de si mesmo. Reis, um "pagão latente, desentendido da vida moderna e desentendido daquela vida antiga, onde devia ter nascido" (apud Cunha, 1994: 161), segundo a descrição que aquele dele faz nas "Notas". António Mora, uma "sombra com veleidades especulativas" que "passava a vida a mastigar Kant" (idem). E Fernando Pessoa ele mesmo, o poeta que

\footnotetext{
2 A edição seguida das "Notas" é a de Teresa Sobral Cunha, em Poemas Completos de Alberto Caeiro, Lisboa, Editorial Presença, 1994, páginas 155 a 177. De acordo com a hipótese do investigador pessoano Jorge Uribe, a redacção das "Notas" terá começado em 1929, estendendo-se pelo menos até 1932.

3 Publicado pela primeira vez em 1989, com o curioso subtítulo "Fernando Pessoa explicado às criancinhas naturais e estrangeiras por M.C.V.".
} 
quando escreve uma quadra, emprega esforços de organização industrial para ver como há de dispor através dela os dezassete raciocínios a que ela é obrigada por lei a conter; que, quando sente qualquer coisa, se põe logo a cortá-la com uma tesoura de cinco críticos, a embrulhar-se em porque é que o segundo verso contém um adjectivo biforme e em ver como é que não sendo «mas» bom português vai conseguir que «senão» tenha uma sílaba só. (apud Cunha, 1994: 172)

São estas, então, as cinco figuras que compõem o simpósio peculiar que ocorre na quinta da tia-avó de Caeiro no Ribatejo, embora o Campos das "Notas" se esforce bastante para reduzir o elenco a quatro elementos, excluindo reiteradamente, e num tom amargo de revanche, Fernando Pessoa que, nas suas palavras, "não existe, propriamente falando" (apud Cunha, 1994: 162). Esta menoridade de Pessoa enquanto discípulo do mestre não incita, no entanto, repercussões de maior na economia narrativa das "Notas", e o espaço de diálogo com Caeiro que lhe é concedido é mais ou menos equivalente ao de Campos, Reis e Mora. Apesar disso, porém, Campos nunca perde uma oportunidade para dar uma alfinetada em Pessoa, sobretudo nos momentos em que intui que aquele não possui a sensibilidade suficiente para se poder tornar discípulo de quem quer que seja. Fernando Pessoa, na sua descrição, "sente as cousas mas não se mexe, nem mesmo por dentro" (apud Cunha, 1994: 160), e isso parece incapacitá-lo para o exercício da idolatria. Por consequência, apenas os outros três parecem habilitados a uma relação substantiva com o mestre. Ou, como resume Campos,

Propriamente falando, Reis, Mora e eu somos três interpretações orgânicas de Caeiro. Reis e eu, que somos fundamentalmente embora diversamente poetas, interpretamos ainda com sujidades do temperamento! Mora, puramente intelectual, interpreta com a razão; se tem sentimento, ou temperamento, anda disfarçado. (apud Cunha, 1994: $164,165)$

Campos parece revoltar-se contra a insensibilidade poética de Pessoa, aludida em vários passos das "Notas" mas, inversamente, gere de modo pacífico a insensibilidade hermenêutica de Mora, talvez por ser mais filosófica do que afectiva. O que conta é que, de diversos modos e em diversos pontos, Campos, que tantas vezes subsumiu Pessoa e apareceu "carnalmente" a Ofélia Queiroz, por exemplo, e a João Gaspar Simões, exerce uma censura deliberada cujo locus deliberativo é o "racionalismo" daquele. ${ }^{4}$ Mas para que três pessoas cheguem a ser uma interpretação orgânica de alguém são

${ }^{4}$ Cf. a propósito, e entre outros exemplos, as Cartas de Amor de Fernando Pessoa e Ofélia Queiroz, editadas por Manuela Parreira da Silva (Lisboa, Assírio \& Alvim, 2012) e a Heteropsicografia de Fernando Pessoa, de João Gaspar Simões (Porto, Editorial Inova, 1973). 
necessários alguns pressupostos, e é justamente a narrativa deste quadro que Álvaro de Campos leva a cabo nas "Notas para a recordação do meu mestre Caeiro".

O exercício de Campos é o de recuperação da atmosfera do simpósio, como descrito, por exemplo, naquele que é tido como um dos modelos maiores da prática do diálogo filosófico, $O$ Banquete de Platão. ${ }^{5}$ O Banquete tem sido descrito em termos temáticos como uma apologia do amor, nas suas formas hetero e homossexual, mas é sobretudo, e a um nível menos superficial de análise, uma imagem da tradição ateniense do debate e do diálogo. É pouco provável que, na quinta em que Caeiro se passeava, algures no Ribatejo, existissem festas do calibre das que são retratadas n'O Banquete, abundantes em música, comida e bebida até altas horas da madrugada. Intuitivamente, a cena ribatejana parecer-nos-á bastante mais plácida e bucólica, distante do sentido orgíaco das celebrações privadas da Antiguidade clássica. Mas independentemente destas diferenças, é precisamente no Ribatejo de Caeiro que Campos reencena as relações de amizade intelectual e de afinidade filosófica que movem Ágaton, Aristodemo, Pausânias ou Sócrates. As "Notas" são, neste sentido preciso, um arremedo de Banquete em que, à falta de cânticos, fruta e vinho, os intervenientes estabelecem um complexo quadro de relações entre si, e entre si e uma figura tutelar, a de Caeiro, que no Ribatejo faz as vezes do Sócrates de Atenas. Apesar das continuidades, porém, as motivações dos dois simpósios parecem, numa primeira análise, diferentes, tanto mais que o próprio Sócrates, quiçá de forma irónica, inutiliza prospectivamente as implicações do seu diálogo, quando afirma

Bom era, Ágaton, que a sabedoria fosse qualquer coisa assim, capaz de deslizar do mais cheio para o mais vazio quando estamos em contacto uns com os outros - tal como nas taças a água desliza, através de fiozinhos de lã, da mais cheia para a mais vazia. Se também isto se passa com o saber, então sou eu quem se congratula com a honra de estar ao teu lado, pois estou convicto de que a sabedoria, vinda de ti em profusão e beleza, irá encher-me até aos bordos! (apud Azevedo, 1991: 32)

Esta talvez-ironia condescendente de Sócrates não tem eco algum no Ribatejo, porque para interpretar, na charneca, parece ser necessário deslizar.

Este deslizamento tem, aparentemente, implicações diferentes para cada um dos heterónimos que Campos coloca no simpósio. Desde logo, porque as pretensões poéticas e filosóficas dos quatro discípulos são bastante diferentes entre si. Campos descobre a verdade de si mesmo e acomoda nas suas sensações a versão pueril do mundo que lhe é ensinada por Caeiro: segundo

\footnotetext{
${ }^{5}$ A edição seguida de O Banquete é a de Maria Teresa Schiappa de Azevedo (tradução, introdução e notas), Lisboa, Edições 70, 1991.
} 
as suas palavras, "[l]ogo que conheci Caeiro, verifiquei-me. (...) [e], daí em diante, por mal ou por bem, tenho sido eu." (apud Cunha, 1994: 162). ${ }^{6}$ António Mora, por seu lado, transforma em sistema as intuições de Caeiro quanto ao conceito de "realidade" (nos Prolegómenos Para Uma Reformação do Paganismo), a partir de uma conversa aparentemente banal com o mestre, que a partir do axioma de que "[a] natureza é partes sem um todo" (apud Cunha, 1994: 171), determina todo o posicionamento filosófico do discípulo. Sem querer, segundo diz, "diminuir o valor realíssimo de António Mora” (idem), Campos conclui que a alteração crucial das posições daquele se origina em Caeiro, rejubilando depois da descrição: “[o] seu a seu dono, e tudo ao meu mestre Caeiro" (ibidem).

Também Fernando Pessoa se emancipou poeticamente depois de ter conhecido Caeiro: “[o]uviu ler O Guardador de Rebanhos. [f]oi para casa com uma febre (a dele), e escreveu, num só lance ou traço, a «Chuva Oblíqua» - os seis poemas" (apud Cunha, 1994: 162). A anatomia deste momento é mais uma das instâncias em que Campos censura Pessoa, para logo a seguir o elogiar moderadamente, como se o azedume se adoçasse com a dose certa de condescendência. Referindo-se ao momento em que Pessoa conheceu Caeiro (o célebre "dia triunfal"), Campos faz o seguinte diagnóstico:

Este homem, tão inutilmente bem dotado, vivendo constantemente na parabulia da sua complexidade, teve naquele momento - também ele - a sua libertação. Se algum dia se esquecer ao ponto de publicar qualquer livro, se o livro for de versos, e vierem datados os pequenos poemas, ver-se-á que há qualquer coisa de diferente nos que têm datas posteriores a 8 de Março de 1914. (apud Cunha, 1994: 173)

Reis, por fim, parece ser capaz de receber na plenitude a sabedoria deslizante do mestre, através de um processo peculiar de transmutação genérica. De acordo com Campos,

Desde que conheceu Caeiro, e lhe ouviu O Guardador de Rebanhos, Ricardo Reis começou a saber que era organicamente poeta. Dizem alguns fisiologistas que é possível a mudança de sexo. Não sei se é verdade, porque não sei se alguma coisa é «verdade». Mas o certo é que Ricardo Reis deixou de ser mulher para ser homem, ou deixou de ser homem para ser mulher - como se preferir - quando teve esse contacto com Caeiro. (apud Cunha, 1994: 161)

Num sentido importante, estes diferentes modos de reagir têm muito a ver com a natureza dos participantes do simpósio. Existe, notoriamente, um

\footnotetext{
${ }^{6} \mathrm{Ou}$, de outro modo, "[p]or mim, antes de conhecer Caeiro, eu era uma máquina nervosa de não fazer coisa nenhuma" (apud Cunha, 1994: 162).
} 
processo de metamorfose em todos eles, de um estado anterior a Caeiro para um estado posterior de libertação, que parece incluir a esperança da paz interior ou, pelo menos, de um módico razoável de conciliação. No caso do relator desta encenação, Álvaro de Campos, essa transformação é tanto pessoal como poética; no caso de Mora, um "tradutor" sistemático do pensamento do mestre, essa transformação é de natureza filosófica e conceptual; no caso de Reis, como se viu, ela é genérica - e sexual; no caso de Fernando Pessoa, ela é estritamente criativa - um encontro propicia uma febre que, por sua vez, se transmuta em poesia. O momento de charneira é, em todos os casos, o contacto directo com o esfíngico Caeiro, assim descrito por Campos:

Primeiro, os olhos azuis de criança que não tem mêdo; depois, os malares já um pouco salientes, a côr um pouco pálida, e o estranho ar grego, que vinha de dentro e era uma calma, e não de fora, porque não era expressão nem feições. (apud Cunha, 1994: 157)

Este momento iniciático tem, apesar das consequências que deslizam de modo diferente para as almas de cada um dos participantes do simpósio, uma característica comum: trata-se de um momento catártico e epifânico - talvez até oracular, se tomarmos pelo pé da letra a descrição física de Caeiro -, cuja projecção para o futuro é sentida de igual modo por todos os heterónimos. Há, neste ponto, um sentido de comunhão e de partilha que é radicalmente diferente dos momentos em que Campos caracteriza, com minúcia, os actores do simpósio.

Esta promessa de futuro, no entanto, é tão despida de pretensões que a sua humilde desfaçatez acrescenta algo ao seu encanto inaugural. Os axiomas de Caeiro, ditos como se fossem "axiomas da terra", parecem fazer da não exigência de uma resposta, ou de um retorno de qualquer espécie, a alavanca para um procedimento hermenêutico que os excede, atingindo o âmago da identidade dos seus destinatários. A estupefacção dos discípulos perante a plácida retórica do mestre é absoluta, como dá conta Campos neste trecho (delicioso) das "Notas":

E eu, desnorteado. «Mas v. não concebe o espaço como infinito? v. não pode conceber o espaço como infinito?» «Não concebo nada como infinito. Como é que eu hei de conceber qualquer coisa como infinito?» «Homem», disse eu, «suponha um espaço. Para além dêsse espaço há mais espaço, para além dêsse mais, e depois mais, e mais, e mais... Não acaba...» «Porquê?» disse o meu mestre Caeiro. Fiquei num terramoto mental. «Suponha que acaba», gritei. «O que há depois?» «Se acaba, depois não há nada», respondeu. Este género de argumentação, cumulativamente infantil e feminina, e portanto irrespondível, atou-me o cérebro durante uns momentos. (apud Cunha, 1994: 159) 
Esta capacidade de "atar o cérebro" dos discípulos faz parte da sensualidade intelectual, despojada e aparentemente não-teleológica, que constitui o caiador como descrito no contexto do simpósio. E neste ponto em particular, o Ribatejo torna-se subitamente muito parecido com Atenas, e a quinta da tia-avó de Caeiro com a casa de Ágaton, pois, como diz Pausânias no seu discurso sobre o amor, "aquele que ama alguém pela beleza do seu carácter, esse permanece fiel pela vida fora, porque se funde com o que é constante" (apud Azevedo, 1991: 44). Ou, à maneira do Ribatejo e nas palavras de Álvaro de Campos, "[o] meu mestre Caeiro era um mestre de toda a gente com capacidade para ter mestre” (apud Cunha, 1994: 161).

De acordo com Agostinho da Silva, Caeiro "substitui o pensamento pela sensação: pensa, como os deuses, pelos pés, pela boca, pelos ouvidos, pelos olhos" (Silva, 1996: 59), numa espécie de orgia iniciática e despretensiosa de sensações que inutiliza prospectivamente a intelectualidade castradora de Fernando Pessoa - que é, segundo a descrição de Campos, "um novêlo embrulhado para o lado de dentro" (apud Cunha, 1994: 158) - e dos restantes heterónimos. No caso particular de Álvaro de Campos, um artista cuja "falsa posição na vida" é descrita por Agostinho da Silva como uma expressão parcial dos sentimentos, num movimento hesitante de vaivém entre a novidade e um desejo de "forma clássica", essa maneira virgem de pensar é todo um descobrimento. Descrevendo o modo como reagiu ao axioma de Caeiro segundo o qual "[t]udo é diferente de nós, e por isso é que tudo existe" (apud Cunha, 1994: 157), Álvaro de Campos produz a seguinte autobiografia, que vale a pena transcrever na íntegra:

Esta frase, dita como se fôsse um axioma da terra, seduziu-me com um abalo, como o de tôdas as primeiras posses, que me entrou nos alicerces da alma. Mas, ao contrário da sedução material, o efeito em mim foi de receber de repente, em tôdas as minhas sensações, uma virgindade que não tinha tido. (idem)

Segundo Agostinho da Silva, foi por estas e por outras que Caeiro "[d]eu a Álvaro de Campos a lição suprema de que a única obrigação que a alguém cabe, o único dever a que não pode faltar, é o ser ele próprio" (Silva, 1996: 71). Neste contexto, a virgindade primordial recém-adquirida por Campos pode ser vista como o caminho para a verdade, ou, na pior das hipóteses, o caminho para fechar o espaço entre as sensações e o raciocínio. Mas por debaixo da filosofia está a vida, e

Assim, Caeiro, num mundo de reflexivos e de metafísicos, era, ou pelo menos pretendia ser, o não-metafísico, o não-discursivo, o não-reflexivo; cumpria-lhe ser calmo, porque o era, cumpria-lhe ser, porque o era, uma coisa entre as coisas. A coragem de ser, eis aí o que daria a Álvaro de Campos o remédio dos seus insondáveis tédios. (Silva, 1996: 72) 
Ao afirmar "[e]u não tenho teorias. [e]u não tenho filosofia. [e]u vejo mas não sei nada" (apud Cunha, 1994: 170), Caeiro faz jus ao nome, caiando a alma díspar de Álvaro de Campos, hesitante entre os desejos e o tédio paralisante que nele se instala pela não concretização daqueles. $O$ grande problema é que, segundo Agostinho da Silva,

A doutrina de Caeiro é tão frágil como a sua saúde: ambas estão ameaçadas por infecções, o raciocínio e a tuberculose, que sendo infecções são fenómenos da vida e têm que ser explicados na vida, mesmo para serem destruídos. (Silva, 1996: 63)

$\mathrm{Na}$ sequência da morte prematura, em que a esfinge de "estranho ar grego" desaparece para dar lugar ao poeta e ao profeta, aquilo que resta a Álvaro de Campos parece ser a tarefa da posteridade. Como amigo maior de Caeiro, e seu mais dedicado discípulo, cabe-lhe recuperar, nas "Notas para a recordação do meu mestre Caeiro", a história de uma amizade espectral que envolveu um conjunto significativo de personalidades. O simpósio ribatejano, como o ateniense, de resto, demonstra o desejo de emulação de uma personalidade superior, respeitada tanto pela sua figura como pelas suas palavras. Mas o Caeiro de Campos e o Sócrates de Platão são, em muitos sentidos, pessoas bastante diferentes. Talvez por isso, Álvaro de Campos tenha sentido necessidade de agir como fiel depositário da herança do seu mestre Caeiro que, mais do que um mestre da retórica, era, no fim de contas, o irmão mais velho (ou, quem sabe, o pai) que Pessoa, Reis, Mora e ele mesmo desejavam.

Parece claro que os afectos desempenham um papel crucial na determinação do equilíbrio de forças do simpósio encenado por Campos no Ribatejo. Mais do que uma disputa entre iguais sobre a natureza e os méritos do amor, como na sua contraparte ateniense, ele é sobretudo um sítio físico, intelectual e sensitivo onde o tópico da fecundação é instrumental para a sua compreensão. Será então o amor, mais do que a filosofia, a "compor" as semelhanças entre Atenas e o Ribatejo, ou entre "antigos" e "modernos"? Segundo Sócrates, no seu discurso,

há homens cuja alma possui uma fecundidade ainda superior à do corpo em criar e produzir o que a ela compete (e o que lhe compete, afinal, gerar, senão a sabedoria e as demais formas de virtude?) - E entre esses tais se contam não apenas todos os poetas criadores de obras, como ainda, no domínio da técnica, todos os artífices reconhecidamente dotados de espírito inventivo. (apud Azevedo, 1991: 80)

De acordo com Álvaro de Campos, “[o] meu mestre Caeiro odiava a ambição. [u]m dia disse-lhe que desejava ser o mais livre do mundo. «Álvaro de Campos», respondeu ele, «você é o que é sem mais nada»" (apud Cunha, 
1994: 174). Deste modo, o "semi-deus criança", como a ele se refere o discípulo, fecunda paradoxalmente em Campos a tal virgindade desconhecida que o instiga a sentir como nunca antes a realidade das coisas. Esta forma de amor parece ser, no simpósio dos heterónimos, a mola catalisadora para um reposicionamento estético, pessoal e identitário que transcende não só a "vontade de Pessoa", como intui Agostinho da Silva, mas, e mais importante, a própria biografia anterior das personagens do teatro pessoano.

No entanto, e curiosamente, essa mesma biografia vem a ser subordinada à poesia, no último fragmento das "Notas para a recordação do meu mestre Caeiro", no qual Campos faz o elogio fúnebre do seu mentor, através de uma gradação enfática:

$\mathrm{O}$ poeta superior diz o que efectivamente sente. $\mathrm{O}$ poeta médio diz o que decide sentir. $O$ poeta inferior diz o que julga que deve sentir. (...) Quando um poeta inferior sente, sente sempre por caderno de encargos. Pode ser sincero na emoção: que importa se o não é na poesia? Há poetas que atiram com o que sentem para o verso: nunca verificaram que o não sentiram. Chora Camões a perda da alma sua gentil; e afinal quem chora é Petrarca. Se Camões tivesse tido a emoção sinceramente sua, teria encontrado uma forma nova, palavras novas - tudo menos o soneto e o verso de dez sílabas. Mas não: usou o soneto em verso, como usaria luto na vida. O meu mestre Caeiro foi o único poeta inteiramente sincero do mundo. (apud Cunha, 1994: 177)

A vida, no contexto deste simpósio, acompanha a arte e a poesia, não sendo no entanto completamente transparente por que lado começam as transformações operadas por Caeiro nos seus quatro companheiros de conversa. O que parece certo, porém, é que uma certa espécie de amizade intelectual, uma forma particular de admiração profunda e a capacidade de receber a sabedoria deslizante de outrem têm a capacidade de gerar poesia e, por isso, vida. Ou será ao contrário?

No simpósio do Ribatejo, e a acreditarmos na descrição inicial de Agostinho da Silva, Caeiro parece fazer as vezes de Pessoa. No caso deste, a urgência de um lado feminino impele-o, na fuga ao suicídio, a parir-se em poetas. No caso de Caeiro, em rigor, é uma forma particular de masculinidade seminal que fecunda os heterónimos, articulando-lhes a vida e a arte no sentido de uma deserção da anterioridade. Nem Pessoa, nem Reis, nem Mora, nem muito menos Campos conseguiram voltar a ser os mesmos depois de Caeiro, o caiador, a cal branca sobre um passado que deixa de se desejar a partir do momento em que se descobre a capacidade para ter um 
mestre. Apesar disso, o mestre deixou relações desiguais. ${ }^{7}$ Campos adora-o, admira Mora, dá em muitos cravos e muitas ferraduras quanto a Reis e deplora Pessoa, dirigindo-lhe uma série de amargos comentários, misturados com opiniões complacentes e acusações acintosas. Parece encenar também, sob a superfície, uma espécie de "romance familiar" à la Freud. ${ }^{8}$

Mas é por isto mesmo que o simpósio faz sentido, e Álvaro de Campos, relatando-o em primeira mão, atribui consequências diferentes a pessoas diferentes que, apesar dessas mesmas diferenças, parecem conviver bem entre si e na relação com o mestre comum que é Caeiro. Isto pelo menos é certo. Mas a partir deste simpósio podemos talvez intuir outras coisas. Por exemplo, que Pessoa tenha uma noção peculiar de criação, em que o parto vem antes da fecundação, precedendo-o de alguma maneira. Ou, dito de outro modo, que Fernando Pessoa mulher tenha tido necessidade de encontrar um homem que lhe fecundasse as criações - sendo ele próprio, claro, uma delas. Ou, da mesma maneira, que o que se pariu precisava de ser corrigido para sobreviver, ainda que à custa da morte do pai. Mas isto são só conjecturas, que eu, de vez em quando, também as sei fazer. ${ }^{9}$

\section{Referências}

CUNHA, Teresa Sobral (recolha, transcrição e notas) (1994). Poemas Completos de Alberto Caeiro, Lisboa, Editorial Presença - Colecção "Ler Pessoa".

PLATÃO (1991). O Banquete, tradução, introdução e notas Maria Teresa Schiappa de Azevedo, Lisboa, Edições 70.

SILVA, Agostinho da (1996). Um Fernando Pessoa, $3^{\text {a }}$ edição, Lisboa, Guimarães Editores [1959].

(C) 2013 Ricardo Namora.

\footnotetext{
${ }^{7}$ E aqui, talvez, sejamos autorizados a desconfiar do declarante Campos da mesma forma que, inicialmente, desconfiámos do declarante Pessoa da célebre carta a Casais Monteiro.

8 Freud chamou "romance familiar" a uma fantasia, consciente e/ou recalcada, segundo a qual a criança imagina ter sido adoptada pelos pais verdadeiros ou, por outro lado, ser fruto de uma relação extraconjugal da mãe. Segundo ele, tal ficção poderia ter vários correlatos, a saber: rivalidade com o progenitor do mesmo sexo, sentimento de vingança contra os pais ou eliminação da concorrência com os irmãos ou irmãs. Se quisermos aplicar, ainda que de modo indicativo, esta sintomatologia ao simpósio do Ribatejo, poderemos talvez colocar a hipótese de que Campos procura eliminar sistematicamente os irmãos - ou, pelo menos, estabelecer uma rivalidade que o beneficia primacialmente a ele-mesmo -, quem sabe para agradar ao pai (Caeiro) numa espécie de adulação post-mortem.

9 Artigo produzido no âmbito do projeto de investigação 'Nenhum Problema Tem Solução: Um Arquivo Digital do Livro do Desassossego' (referência PTDC/CLELLI/118713/2010). Projeto do Centro de Literatura Portuguesa financiado pela FCT e cofinanciado pelo FEDER, através do Eixo I do Programa Operacional Fatores de Competitividade (POFC) do QREN, COMPETE: FCOMP-01-0124-FEDER-019715.
} 